\title{
A Longitudinal Genetic Study of Uric Acid and Liver Enzymes in Adolescent Twins
}

\author{
Rita P. S. Middelberg, ${ }^{1,2}$ Sarah E. Medland, ${ }^{1,3}$ Nicholas G. Martin,' and John B. Whitfield ${ }^{1,4}$ \\ 'Genetic Epidemiology Unit, Queensland Institute of Medical Research, Brisbane, Australia \\ ${ }^{2}$ School of Medicine, University of Queensland, Brisbane, Australia \\ ${ }^{3}$ Virginia Institute of Psychiatric and Behavioral Genetics, Virginia Commonwealth University, Richmond,Virginia, United States of America \\ ${ }^{4}$ Biochemistry Department, Royal Prince Alfred Hospital, Sydney, Australia
}

B iochemical traits such as plasma alanine aminotransferase (ALT), aspartate aminotransferase (AST), gamma glutamyltransferase (GGT) and uric acid are associated with obesity, and with risk of cardiovascular disease, metabolic syndrome and diabetes. Each is subject to genetic influences, but little is known about changes in genetic and environmental influences on these traits over time. We investigated the contribution of genetic and environmental influences to variation in these biochemical traits in adolescent twins and their nontwin siblings from 965 twin families. Twins were studied at ages 12,14 and 16 years. Multivariate genetic models that included effects of age and sex were fitted to determine whether the same or different genetic or environmental factors influence each trait at different ages. Results showed that the genetic factors influencing AST, ALT, GGT and uric acid change over time during adolescence, and that the magnitude of these effects differs between males and females. The nonshared environment effects were generally time specific. There are developmental changes in genes affecting these traits during adolescence.

A number of biochemical components in serum are known to be associated with obesity, prediabetic states, or risk of cardiovascular disease. The best studied in relation to cardiovascular disease are the low-density lipoprotein and high-density lipoprotein components of cholesterol (LDL-C and HDL-C). Nevertheless, other biochemical markers show robust associations with risk of cardiovascular disease, and cluster together, partly because of associations with obesity, insulin resistance and the metabolic syndrome. This group includes enzymes used as liver function tests - gammaglutamyl transferase (GGT), alanine aminotransferase (ALT) and aspartate aminotransferase (AST), triglyceride and uric acid.

Most of these show changes in mean concentration with age, and adult male-female differences which are absent in children. Because of the long-term nature of cardiovascular and metabolic risk, and evidence that structural changes in arteries can be found in adolescents, study of causes of variation in these risk factors needs to take account of developmental changes across puberty and adolescence.

There is substantial epidemiological evidence showing both cross-sectional and prospective associations between these markers and disease. Opinion on whether serum uric acid is a true risk factor for mortality and cardiovascular disease, or is simply associated with other risk factors, is divided, but there is no doubt that it is associated with the metabolic syndrome (Liese et al., 1999; Tomita et al., 2000). Serum gammaglutamyl transferase (GGT) has been shown to be prospectively associated with cardiovascular disease (Cutrin et al., 2000; Emdin et al., 2001; Hood et al., 1990; Lee et al., 2006; Pompella et al., 2004; Ruttmann et al., 2005; Wannamethee et al., 1995), hypertension (Lee et al., 2003b; Miura et al., 1994) and diabetes (Lee et al., 2003a; Lee et al., 2003b; Lee et al., 2004; Meisinger et al., 2005; Nakanishi et al., 2003; Perry et al., 1998; Wannamethee et al., 2005; Whitfield, 2001). Serum GGT is significantly correlated with total or LDL cholesterol, high-density lipoprotein (inversely), and particularly with triglycerides (Whitfield, 2001; Whitfield et al., 2002). In the general population, GGT is significantly correlated with other liver enzymes AST and ALT (Arndt et al., 1998; Whitfield et al., 2002), and these too have been reported to predict cardiovascular and diabetes risk, and mortality (Arndt et al., 1998; Nannipieri et al., 2005; Vozarova et al., 2002; Wannamethee et al., 2005). In addition to these, serum triglyceride is part of the definition of the metabolic syndrome, and is correlated with the liver enzymes and uric acid; like uric acid it is associated with cardiovascular risk, but may not be an independent risk factor.

Received: 16 July, 2007; accepted 27 July 2007.

Address for correspondence: Rita P. S. Middelberg, Genetic Epidemiology Unit, Queensland Institute of Medical Research, PO Royal Brisbane Hospital, Queensland 4029, Australia. E-mail: rita.middelberg@qimr.edu.au 
Therefore the causes of variation in these biochemical characteristics are of considerable interest. Sex differences develop around the time of puberty (Lockitch et al., 1988b; Lockitch et al., 1988a) and decrease after menopause (Leonard, 1973; Wilding et al., 1972). A full understanding requires analysis of longitudinal data in genetically informative subjects such as twins, siblings or other family members, and ultimately genetic linkage and association studies. Previous work has established the importance of genetic variation in adults, showing significant heritability for serum uric acid (Friedlander et al., 1988; Kalousdian et al., 1987; Whitfield \& Martin, 1983); and for GGT, ALT and AST (Bathum et al., 2001; Whitfield et al., 2002).

However, little is known about changes of genetic and environmental influences on these variables over time in adults, or in particular in adolescents. Repeated measures on the same individuals on different occasions permit study of whether the same or different genes influence a trait at different ages. They can also test whether nonshared environmental effects are solely a consequence of measurement error and biological variation, or also reflect relatively long-term differences in the individual environment. Data on LDL and HDL cholesterol, and triglycerides, have been presented elsewhere (Middelberg et al., 2007). The aims of the present report are to use repeated-measures data for biochemical variables associated with obesity (uric acid, ALT, AST, GGT) to investigate first, whether the genes affecting these traits vary with age in adolescence; and second, whether nongenetic (environmental) effects persist over time. This is a necessary step on the way to identifying loci and gene polymorphisms which affect these characteristics and their changes over time.

\section{Materials and Methods \\ Subjects}

The characteristics of the participants in this study have been described previously (Middelberg et al., 2007). Briefly, the data come from three studies of adolescent twins and their nontwin siblings living in south-east Queensland, Australia: the mole study (McGregor et al., 1999; Zhu et al., 1999); the cognition (or memory, attention and problem solving [MAPS]) study (Wright et al., 2001) and the Twin Adolescent study (Wright \& Martin, 2004). Additional blood samples were collected from some twins, and also from their other siblings. Adolescent twins were initially recruited in 1992, with additional pairs added subsequently. A total of 965 families participated across all three measurement occasions (Middelberg et al., 2007). For each of these studies, participants and their parents gave informed consent to the questionnaire, interview, and blood collection, and all studies were approved by the QIMR Human Research Ethics Committee.
Zygosity assignment in all same sex twin pairs was confirmed by genotyping a panel of nine highly polymorphic microsatellite markers.

\section{Laboratory Measurements}

Serum was separated from the blood samples and stored at $-70{ }^{\circ} \mathrm{C}$ until analyzed. Serum uric acid, AST, ALT and GGT were measured using Roche methods on a Hitachi 917 Analyzer (Roche Diagnostics, Basel, Switzerland). These biochemical analyses were performed on samples from the adolescent twins and their siblings.

\section{Statistical Analysis}

Distributions of the variables were examined. If frequency distributions were skewed an appropriate transformation was used before further analysis. All references to serum AST, ALT and GGT are to logtransformed values unless specified otherwise. Families where any member had a Z-score of greater than 3.5 were excluded from the analysis for that variable (uric acid: 4 families; AST: 11 families; ALT: 10 families; GGT: 15 families).

Data processing and descriptive analyses were done with STATA version 7.0 (StataCorp, 1997). Quantitative genetic and environmental model fitting (Neale \& Cardon, 1992) was performed using the program, $M x$ version 1.63 (Neale, 1999). Prior to genetic modelling, tests of distributional assumptions (i.e. that all twins and siblings have the same means and variances) were performed. The variables were also adjusted for the effects of age, squared age $\left(\operatorname{age}^{2}\right)$, sex, sex $\times$ age and sex $\times \operatorname{age}^{2}$.

In order to investigate the relative magnitude of genetic and environmental influences across the three occasions, we fitted separate Cholesky (triangular) decompositions to the data for each of the four traits. In addition to providing information regarding the importance of genetic and environmental effects, these analyses allowed us to characterize the nature of the covariation across time. Thus, a first factor may potentially contribute to all three measurement occasions; a second factor to the second and third measurement occasions; while a third factor is specific to the last measurement occasion. The models were fitted by the method of full information maximum-likelihood (FIML), which makes use of every available data point, allows for covariate correction, and takes account of missingness.

In order to use all available data from the male and female twins and their nontwin siblings, we utilized the implementation of the nonscalar sex limitation model parameterized by Medland (2004). In this model the magnitude of additive genetic, common, and unique environmental variances are estimated separately for males and females. By including the data from opposite sex sibling pairs, we were able to model an additional set of additive genetic effects for one sex, allowing a test of the 
hypothesis that the genes influencing the trait differ between males and females. The variance and covariance terms of this model are summarized below:

If $\mathrm{i}$ and $\mathrm{j}$ are both male,

$\sigma_{A m}^{2}+\sigma_{A \text { sex-specific }}^{2}+\sigma_{C m}^{2}+\sigma_{E m}^{2}$ if $i=j$

$\pi_{i j} \sigma_{A m}^{2}+\pi_{i j} \sigma_{\text {A sex-specific }}^{2}+\sigma^{2}$ if $i \neq j$

If $\mathrm{i}$ and $\mathrm{j}$ are both female,

$\sigma_{A f}^{2}+\sigma_{C f}^{2}+\sigma_{E f}^{2}$ if $i=j$

$\pi_{i j} \sigma_{A f}^{2}+\sigma_{C f}^{2}$ if $i \neq j$

and, for brothers and sisters,

$\pi_{i j} \sigma_{A m} \sigma_{A f}+\sigma_{C m} \sigma_{C f}$

where, $\pi_{i j}$ is the coefficient of relationship, equal to 1 for $\mathrm{MZ}$ pairs and $1 / 2$ for DZ twins and full siblings; $\sigma_{A m}^{2}, \sigma_{C m}^{2}, \sigma_{E m}^{2}$ are the additive genetic, common environmental, and unique environmental effects in males; $\sigma_{\text {A sex-specific }}^{2}$ are the additional set of additive genetic effects (estimated here in males); and $\sigma_{A f}^{2}$, $\sigma_{C f}^{2}, \sigma_{E f}^{2}$ are the additive genetic, common environmental, and unique environmental effects in females.

However, this model contains a large number (42) of estimated variance parameters. Thus, we fitted a series of simplified models to the data to determine whether all sources of variance were required to accurately describe the data. These submodels and the results of the model fitting are described in the results section below. To compare nested models, the likelihood ratio chi-square test (i.e., a difference between $-2 \log$ likelihood of the full model from that of a restricted model) was used. Given the large number of statistical tests performed, we adopted an $\alpha$ level of .01. For the final model, 95\% confidence intervals for all estimates of the path coefficients were computed.

\section{Results}

\section{General Characteristics}

Means and standard deviations of all traits for males and females are listed by age in Table 1. For uric acid, AST, and GGT, the means of the females and males trend in opposite directions with age. Phenotypic correlations of each trait across ages 12,14, and 16 are shown in Table 2. Correlations between measurement occasions were around .6 for uric acid, .3 for AST, .4 for ALT and .5 for GGT. Twin pair correlations according to zygosity group, adjusted for the age-, age $^{2}-$, and sex-, age $\times$ sex, age ${ }^{2} \times$ sex adjusted mean for each time point, are presented in Table 3. For all traits and at all ages, the correlation between $\mathrm{MZ}$ twins was generally high (greater than .6). The corresponding DZ correlations were lower, suggesting genetic influences at all ages. Moreover, the $\mathrm{MZ}$ pair correlations at each age were stronger than the within-individual correlations across ages, suggesting the existence of age-specific genetic effects. A striking feature is the lower value of the opposite sex twin-pair correlation, indicating that for some variables different genetic influences may be operating in boys and girls.

\section{Table 1}

Means and Standard Deviations (SD) for Females and Males at Ages 12,14 and 16

\begin{tabular}{lcccccc}
\hline \multirow{2}{*}{ Variables } & \multicolumn{3}{c}{ Females } & \multicolumn{3}{c}{ Males } \\
\hline \multicolumn{1}{l}{$N$} & Mean & $S D$ & $N$ & Mean & $S D$ \\
\hline Uric acid (mmol/I) & & & & & & \\
12 & 748 & 0.254 & 0.052 & 738 & 0.262 & 0.070 \\
14 & 609 & 0.261 & 0.050 & 598 & 0.302 & 0.070 \\
16 & 659 & 0.256 & 0.054 & 648 & 0.331 & 0.068 \\
ALT (IU/I) (log) & & & & & & \\
12 & 742 & 1.097 & 0.178 & 732 & 1.156 & 0.196 \\
14 & 603 & 1.052 & 0.192 & 594 & 1.128 & 0.213 \\
16 & 653 & 1.118 & 0.154 & 638 & 1.223 & 0.174 \\
AST (IU/I) (log) & & & & & & \\
12 & 743 & 1.346 & 0.119 & 730 & 1.404 & 0.099 \\
14 & 599 & 1.285 & 0.107 & 595 & 1.371 & 0.109 \\
16 & 656 & 1.288 & 0.103 & 643 & 1.370 & 0.107 \\
GGT (IU/I) (log) & & & & & & \\
12 & 743 & 1.087 & 0.127 & 731 & 1.097 & 0.121 \\
14 & 602 & 1.024 & 0.121 & 595 & 1.113 & 0.120 \\
16 & 654 & 1.047 & 0.155 & 643 & 1.153 & 0.157 \\
\hline
\end{tabular}

Note: AST: aspartate aminotransferase; ALT: alanine aminotransferase; GGT: gamma glutamyltransferase.

\section{Table 2}

Phenotypic Correlations of Variables Between Ages 12, 14 and 16 by Sex

\begin{tabular}{cccc}
\hline & 12 & 14 & 16 \\
\hline Uric acid & & & \\
12 & $(760,747)$ & $.64(423)$ & $.47(276)$ \\
14 & $.66(460)$ & $(611,598)$ & $.60(337)$ \\
16 & $.65(278)$ & $.59(355)$ & $(662,648)$ \\
ALT $(\log )$ & & & \\
12 & $(754,741)$ & $.45(419)$ & $.43(270)$ \\
14 & $.43(455)$ & $(605,594)$ & $.38(331)$ \\
16 & $.37(275)$ & $.36(350)$ & $(657,638)$ \\
AST $(\log )$ & & & \\
12 & $(755,739)$ & $.39(420)$ & $.47(274)$ \\
14 & $.34(451)$ & $(601,595)$ & $.23(334)$ \\
16 & $.33(278)$ & $.33(352)$ & $(660,643)$ \\
GGT (log) & & & \\
12 & $(755,740)$ & $.59(421)$ & $.58(274)$ \\
14 & $.50(454)$ & $(604,595)$ & $.63(335)$ \\
16 & $.54(280)$ & $.56(355)$ & $(658,643)$ \\
\hline
\end{tabular}

Note: Results for women are shown below the bold diagonals and for men above. Numbers on which correlations are based are shown in parenthesis; numbers on the diagonals are total numbers for females and males at that age.

\section{Genetic Analyses}

For each trait, the full multivariate Cholesky decomposition described above was fitted to the longitudinal data. We followed the same process of model simplification for all traits. The results of the model fitting procedure are presented in Table 4. Standardized path 
Table 3

Sibling Correlations for Biochemical Traits at Age 12, 14 and 16 by Zygosity

\begin{tabular}{|c|c|c|c|c|c|}
\hline \multirow[b]{2}{*}{ Age } & \multicolumn{2}{|c|}{$\mathrm{MZ}$ twin correlation } & \multicolumn{3}{|c|}{ DZ twin, twin-sibling and sibling-sibling correlations } \\
\hline & Female & Male & Female & Male & Opposite sex \\
\hline \multicolumn{6}{|c|}{ Uric acid } \\
\hline 12 & $.826(.769, .867)$ & $.867(.816, .901)$ & $.362(.247, .467)$ & $.391(.273, .496)$ & $.354(.257, .439)$ \\
\hline 14 & $.844(.789, .883)$ & $.797(.721, .850)$ & $.436(.289, .557)$ & $.501(.356, .616)$ & $.244(.113, .362)$ \\
\hline 16 & $.737(.658, .797)$ & $.809(.746, .854)$ & $.493(.356, .602)$ & $.400(.248, .528)$ & $.377(.274, .468)$ \\
\hline \multicolumn{6}{|c|}{ ALT (log) } \\
\hline 12 & $.761(.679, .820)$ & $.858(.801, .896)$ & $.517(.412, .605)$ & $.627(.534, .700)$ & $.439(.345, .520)$ \\
\hline 14 & $.734(.646, .798)$ & $.787(.710, .841)$ & $.527(.371, .643)$ & $.682(.584, .756)$ & $.462(.348, .557)$ \\
\hline 16 & $.513(.387, .615)$ & $.731(.645, .795)$ & $.467(.317, .585)$ & $.216(.034, .379)$ & $.346(.234, .442)$ \\
\hline \multicolumn{6}{|c|}{ AST (log) } \\
\hline 12 & $.701(.605, .770)$ & $.790(.709, .845)$ & $.343(.227, .446)$ & $.433(.325, .526)$ & $.321(.214, .414)$ \\
\hline 14 & $.623(.499, .713)$ & $.707(.611, .776)$ & $.398(.226, .533)$ & $.434(.285, .553)$ & $.275(.151, .386)$ \\
\hline 16 & $.645(.546, .721)$ & $.595(.474, .685)$ & $.375(.199, .513)$ & $.437(.305, .546)$ & $.224(.078, .354)$ \\
\hline \multicolumn{6}{|c|}{ GGT (log) } \\
\hline 12 & $.610(.494, .698)$ & $.813(.742, .861)$ & $.284(.166, .392)$ & $.479(.358, .576)$ & $.313(.223, .395)$ \\
\hline 14 & $.761(.678, .819)$ & $.766(.677, .825)$ & $.251(.056, .417)$ & $.303(.139, .443)$ & $.299(.190, .398)$ \\
\hline 16 & $.685(.592, .754)$ & $.782(.712, .831)$ & $.351(.172, .493)$ & $.360(.194, .497)$ & $.282(.164, .387)$ \\
\hline
\end{tabular}

Note: $95 \%$ confidence intervals for the correlation coefficients are shown in parentheses. MZ, monozygotic; DZ, dizygotic.

coefficients (and 95\% confidence intervals) from the final models are given in Table 5 . We began by testing the whether the same genes were influencing the traits in males and females, by dropping the additional sexspecific genetic effects from the model. These additional genetic effects could be dropped for all traits without significantly reducing the fit of the model.

Following this, we formally tested for sex differences in the magnitude of the genetic and environmental variance components, by setting the estimates to be equal across sexes. Despite the omnibus nature of this test and the high degrees of freedom (18), a model in which male and female parameters were equated did not adequately fit the data for any trait, indicating highly significant differences in the magnitudes of genetic and environmental effects.

We then tested whether common environmental or additive genetic effects alone were sufficient to account for the covariation between siblings. As expected, given the differences between $\mathrm{MZ}$ and $\mathrm{DZ}$ correlations, a purely environmental model (CE) provided a poor fit of the data for all four traits. However, for GGT, all common environmental effects could be dropped without significantly reducing the fit of the model, indicating that additive genetic effects could adequately account for the sibling covariation on this measure. This was not the case for AST, ALT, or uric acid concentration. No other model simplification was possible for GGT, thus the best fitting model included Cholesky decompositions of $\mathrm{A}$ and $\mathrm{E}$ in which the magnitudes of the effects were allowed to differ between males and females.
As neither an $\mathrm{AE}$ nor a $\mathrm{CE}$ model provided a good summary of AST, ALT, or uric acid, we continued the model fitting process with these variables. We next tested whether the entire Cholesky structure was required to summarize the unique environmental variance. For AST, ALT and uric acid, we were able to reduce the $\mathrm{E}$ component from six to three parameters, each specific to a time point. This indicated that there was no significant covariation in measurement error or nonshared environmental influences across time points on these measures. For AST and uric acid, we were able to simplify the common environmental structure to a single factor that influenced all three time points. For ALT, although we were unable to simplify the common environmental structure, we could reduce the additive genetic structure to a single factor that influenced all three time points.

\section{$\overline{\text { Discussion }}$}

Study of the genetic control of metabolism over a period of change and development such as adolescence is of fundamental biological interest, and when the characteristics studied are associated with disease, or affect the risk of its development, there are important practical implications. One important objective is to characterize the genes and polymorphisms that affect such characteristics, and their changes through life. How far this can be achieved will depend on the number of relevant polymorphisms and the magnitude of the effects of each, but there can be no doubt that use of an inappropriate model will produce misleading conclusions and misuse of resources. The results of this study suggest that gene effects vary across time 


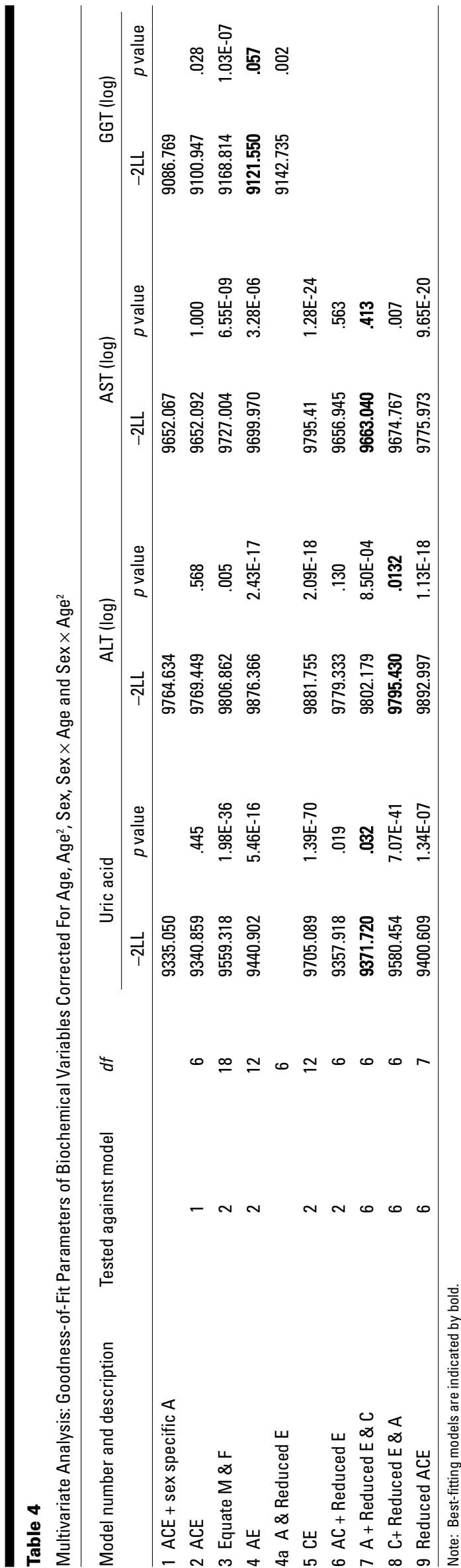

and between the sexes, and genetic linkage or association studies will need to take that into account.

Comparison of the MZ correlations in Table 3 with the correlations of each variable across time in Table 2 shows that similarity within MZ pairs at any age is substantially greater than the similarity within individuals at different ages. This is only explicable by postulating strong gene or shared-environment effects at all ages, but with the nature of these influences changing with age. The quantitative aspects of this, and the mix of gene and shared-environment effects, are displayed in Table 5. It should be noted that early genetic effects do persist across time, but for AST, GGT, and uric acid they are supplemented, and therefore, to some extent displaced, by new ones coming in at ages 14 and 16 . Turning to specific results, the heritabilities of these characteristics were generally high; up to $80 \%$, with the exception of ALT at about $40 \%$ (see Table 5). The magnitude of genetic effects differed in their degree between males and females, and in general genetic effects were larger in males. However, there was no evidence that the genes influencing these traits differ between the sexes.

There was no evidence of covariation among the nonshared environmental effects for ALT, AST, or uric acid. However, small but persistent unique environmental effects, accounting for $0.4 \%$ to $4.4 \%$ of variance, were observed for GGT. While confidence intervals surrounding some path coefficients included zero, attempting to drop these covariance paths from the model did result in a significant reduction in model fit.

Environmental effects shared by members of a twin pair or sibship, on the other hand, were found for uric acid, AST, and ALT. These effects were not significant for GGT. For uric acid and AST, a single common environmental factor was sufficient to summarize these effects; but this was not the case for ALT, which is strongly correlated with AST. At these ages, when practically all the study participants would have been living in a family environment shared by their cotwins or siblings, differences in diet between families are likely to be important. For example, differences in the purine content of the shared diet could affect uric acid. However, in the absence of dietary data, we cannot be sure that this is the explanation, and it is not clear how shared diet or lifestyle could produce the shared environmental effects on ALT and AST.

There are few other studies to compare our results against. There is evidence of age-specific genetic effects for lipids (Middelberg et al., 2007; Nance et al., 1998; Snieder et al., 1999), but longitudinal study of other biochemical traits is very limited.

Although the primary aim of our work is identification of genes that affect biochemical characteristics, environmental influences or gene-environment interactions must also be characterized, as they may be more susceptible to modification. Data from twins and sibling raised together cannot provide a general test of 
Table 5

Multivariate Analysis: Standardised Path Coefficients from the Final Model for Uric Acid, log ALT, log AST and log GGT

\begin{tabular}{|c|c|c|c|c|c|c|c|c|c|}
\hline \multirow[t]{2}{*}{ Time point } & \multicolumn{3}{|c|}{ Additive genetic effects } & \multicolumn{3}{|c|}{ Common environmental effects } & \multicolumn{3}{|c|}{ Unique environmental effects } \\
\hline & $\mathrm{A} 1$ & $\mathrm{~A} 2$ & A3 & $\mathrm{C} 1$ & $\mathrm{C} 2$ & C3 & E1 & E2 & E3 \\
\hline \multicolumn{10}{|c|}{ Uric acid — females } \\
\hline 1 & $.91(.87, .94)$ & & & $-.06(-.24, .17)$ & & & $.41(.35, .47)$ & & \\
\hline 2 & $.68(.55, .79)$ & $.40(.16, .64)$ & & $.50(.27, .64)$ & & & & $.36(.31, .43)$ & \\
\hline 3 & $.58(.42, .69)$ & $-.27(-.63, .15)$ & $.27(-.11, .51)$ & $.57(.23, .71)$ & & & & & $.43(.37, .49)$ \\
\hline \multicolumn{10}{|c|}{ Uric acid - males } \\
\hline 1 & $.92(.88, .95)$ & & & $-.12(-.28, .07)$ & & & $.37(.31, .43)$ & & \\
\hline 2 & $.64(.56, .71)$ & $.57(.38, .66)$ & & $-.28(-.48,-.05)$ & & & & $.43(.38, .49)$ & \\
\hline 3 & $.41(.30, .52)$ & $.50(.31, .62)$ & $.61(.52, .69)$ & $-.19(-.42, .03)$ & & & & & $.41(.36, .48)$ \\
\hline \multicolumn{10}{|c|}{ ALT $(\log )$ — females } \\
\hline 1 & $.78(.67, .86)$ & & & $.41(.22, .55)$ & & & $.48(.42, .55)$ & & \\
\hline 2 & $.44(.27, .57)$ & & & $.33(.09, .57)$ & $.59(.46, .68)$ & & & $.59(.52, .66)$ & \\
\hline 3 & $.29(.13, .44)$ & & & $.37(.15, .55)$ & $.20(.02, .35)$ & $.46(.29, .59)$ & & & $.73(.65, .80)$ \\
\hline \multicolumn{10}{|c|}{ ALT $(\log )$ - males } \\
\hline 1 & $.70(.55, .83)$ & & & $.58(.40, .71)$ & & & $.40(.34, .48)$ & & \\
\hline 2 & $.74(.61, .84)$ & & & $.03(-.24, .26)$ & $.50(.30, .64)$ & & & $.45(.39, .51)$ & \\
\hline 3 & $.61(.49, .74)$ & & & $-.02(-.22, .17)-$ & $-.07(-.27, .12)$ & $.49(.28, .62)$ & & & $.61(.54, .69)$ \\
\hline \multicolumn{10}{|c|}{ AST $(\log )$ — females } \\
\hline 1 & $.84(.78, .88)$ & & & $.01(-.24, .28)$ & & & $.54(.47, .61)$ & & \\
\hline 2 & $.53(.34, .67)$ & $-.15(-.42, .28)$ & & $.48(.25, .66)$ & & & & $.68(.61, .75)$ & \\
\hline 3 & $.45(.31, .57)$ & $-.50(-.70,-.07)$ & $.44(.03, .65)$ & $.12(-.19, .45)$ & & & & & $.58(.51, .66)$ \\
\hline \multicolumn{10}{|c|}{ AST $(\log )$ — males } \\
\hline 1 & $.87(.79, .91)$ & & & $-.15(-.33, .04)$ & & & $.47(.40, .57)$ & & \\
\hline 2 & $.40(.28, .53)$ & $.71(.49, .81)$ & & $.22(-.14, .50)$ & & & & $.54(.47, .62)$ & \\
\hline 3 & $.36(.22, .48)$ & $.38(.15, .63)$ & $.46(-.01, .66)$ & $-.43(-.62,-.17)$ & & & & & $.58(.51, .65)$ \\
\hline \multicolumn{10}{|c|}{ GGT $(\log )$ - females } \\
\hline 1 & $.81(.74, .85)$ & & & & & & $.59(.52, .67)$ & & \\
\hline 2 & $.60(.50, .69)$ & $.65(.55, .72)$ & & & & & $.08(-.01, .18)$ & $.46(.39, .54)$ & \\
\hline 3 & $.64(.51, .75)$ & $.32(.16, .46)$ & $.47(.34, .57)$ & & & & $.16(.01, .29)$ & $.06(-.07, .20)$ & $.50(.43, .57)$ \\
\hline \multicolumn{10}{|c|}{ GGT $(\log )$ — males } \\
\hline 1 & $.89(.85, .92)$ & & & & & & $.45(.39, .53)$ & & \\
\hline 2 & $.71(.62, .79)$ & $.48(.33, .59)$ & & & & & $.09(-.05, .23)$ & $.50(.42, .60)$ & \\
\hline 3 & $.68(.56, .78)$ & $.15(-.07, .35)$ & $.53(.40, .63)$ & & & & $.06(-.10, .22)$ & $.21(.10, .32)$ & $.42(.35, .50)$ \\
\hline
\end{tabular}

gene-environment interaction effects, although specific hypotheses about measured environmental factors and their interaction with genotype can be addressed. Environmental effects not shared within families can be identified, and longitudinal data allow us to determine whether they are constant across time. If they are not, as seen here for ALT, AST and uric acid, they are unlikely to have important effects on long-term risk. Even when present, as for GGT, they have only minor effects compared to other sources of variation.

A major strength of this study is that the sample is large and longitudinal. To our knowledge, this is the first study of age-dependent genetic influences on these biochemical traits. The results can be used as a guide for future quantitative studies on the genetics of these markers or precursors of obesity-associated and cardiovascular disease. In general, multiple measurements across time should lead to increased power for genetic linkage and association studies (Martin et al. 1997), but this assumes that the same genes are acting at all ages - which is not the case here. Nevertheless, elucidation of the developmental changes in gene effects remains a stimulating project, and should provide insight into the processes which can affect these markers of disease risk.

\section{$\overline{\text { Acknowledgments }}$}

We are grateful to the twins and their families for their generous participation in these studies. We would like to thank Ann Eldridge and Marlene Grace for the collection of data; Megan Campbell and Anjali Engan for managing sample processing and preparation; Harry 
Beeby for integrating the data; Veronica Dy and Jole Bojovic of the Biochemistry Department of Royal Prince Alfred Hospital for biochemical analysis; and Kate Morley and Belinda Cornes for their helpful advice. Financial support was provided by grants from the National Health and Medical Research Council (241944 and 389875). RPSM was supported by a Dora Lush NHMRC Scholarship (339484). SEM was supported by an NHMRC Sidney Sax Public Health Fellowship (443036).

\section{References}

Arndt, V., Brenner, H., Rothenbacher, D., Zschenderlein, B., Fraisse, E., \& Fliedner, T. M. (1998). Elevated liver enzyme activity in construction workers: Prevalence and impact on early retirement and all-cause mortality. International Archives of Occupational and Environmental Health, 71, 405-412.

Bathum, L., Petersen, H. C., Rosholm, J. U., Hyltoft, P. P., Vaupel, J., \& Christensen, K. (2001). Evidence for a substantial genetic influence on biochemical liver function tests: Results from a population-based Danish twin study. Clinical Chemistry, 47, 81-87.

Cutrin, J. C., Zingaro, B., Camandola, S., Boveris, A., Pompella, A., \& Poli, G. (2000). Contribution of gamma glutamyl transpeptidase to oxidative damage of ischemic rat kidney. Kidney International, 57, 526-533.

Emdin, M., Passino, C., Michelassi, C., Titta, F., L'abbate, A., Donato, L., Pompella, A., \& Paolicchi, A. (2001). Prognostic value of serum gamma-glutamyl transferase activity after myocardial infarction. European Heart Journal, 22, 1802-1807.

Friedlander, Y., Kark, J. D., \& Stein, Y. (1988). Family resemblance for serum uric acid in a Jerusalem sample of families. Human Genetics, 79, 58-63.

Hood, B., Kjellstrom, T., Ruter, G., \& Kristenson, H. (1990). [Serum cholesterol, serum triglyceride, alcohol, myocardial infarction and death (1): Increased serum GT is strongly related to alcoholinduced diseases]. Lakartidningen, 87, 3289-3290, 3293.

Kalousdian, S., Fabsitz, R., Havlik, R., Christian, J., \& Rosenman, R. (1987). Heritability of clinical chemistries in an older twin cohort: The NHLBI Twin Study. Genetic Epidemiology, 4, 1-11.

Lee, D. H., Ha, M. H., Kim, J. H., Christiani, D. C., Gross, M. D., Steffes, M., Blomhoff, R., \& Jacobs, D. R., Jr. (2003a). Gamma-glutamyltransferase and diabetes: A 4-year follow-up study. Diabetologia, 46, 359-364.

Lee, D. H., Jacobs, D. R., Jr., Gross, M., Kiefe, C. I., Roseman, J., Lewis, C. E., \& Steffes, M. (2003b). Gamma-glutamyltransferase is a predictor of incident diabetes and hypertension: The Coronary Artery Risk Development in Young Adults (CARDIA) Study. Clinical Chemistry, 49, 1358-1366.
Lee, D. H., Silventoinen, K., Hu, G., Jacobs, D. R., Jr., Jousilahti, P., Sundvall, J., \& Tuomilehto, J. (2006). Serum gamma-glutamyltransferase predicts nonfatal myocardial infarction and fatal coronary heart disease among 28,838 middle-aged men and women. European Heart Journal, 27, 2170-2176.

Lee, D. H., Silventoinen, K., Jacobs, D. R., Jr., Jousilahti, P., \& Tuomileto, J. (2004). GammaGlutamyltransferase, obesity, and the risk of type 2 diabetes: Observational cohort study among 20,158 middle-aged men and women. The Journal of Clinical Endocrinology and Metabolism, 89, 5410-5414.

Leonard, P. J. (1973). The effect of age and sex on biochemical parameters in blood of healthy subjects. In G. Siest (Ed.), Reference values in human chemistry (pp. 134-140). Basel, Switzerland: Karger.

Liese, A. D., Hense, H. W., Lowel, H., Doring, A., Tietze, M., \& Keil, U. (1999). Association of serum uric acid with all-cause and cardiovascular disease mortality and incident myocardial infarction in the MONICA Augsburg cohort: World Health Organization Monitoring Trends and Determinants in Cardiovascular Diseases. Epidemiology, 10, 391-397.

Lockitch, G., Halstead, A. C., Albersheim, S., MacCallum, C., \& Quigley, G. (1988a). Age- and sexspecific pediatric reference intervals for biochemistry analytes as measured with the Ektachem-700 analyzer. Clincal Chemistry, 34, 1622-1625.

Lockitch, G., Halstead, A. C., Wadsworth, L., Quigley, G., Reston, L., \& Jacobson, B. (1988b). Age- and sexspecific pediatric reference intervals and correlations for zinc, copper, selenium, iron, vitamins $\mathrm{A}$ and $\mathrm{E}$, and related proteins. Clincal Chemistry, 34, 1625-1628.

Martin, N., Boomsma, D., \& Machin, G. (1997). A twinpronged attack on complex traits. Nature Genetics, 17, 387-392.

McGregor, B., Pfitzner, J., Zhu, G., Grace, M., Eldridge, A., Pearson, J., Mayne, C., Aitken, J. F., Green, A. C., \& Martin, N. G. (1999). Genetic and environmental contributions to size, color, shape, and other characteristics of melanocytic naevi in a sample of adolescent twins. Genetic Epidemiology, 16, 40-53.

Medland, S. E. (2004). Alternate parameterization for scalar and non-scalar sex-limitation models in $\mathrm{Mx}$. Twin Research, 7, 299-305.

Meisinger, C., Lowel, H., Heier, M., Schneider, A., \& Thorand, B. (2005). Serum gamma-glutamyltransferase and risk of type 2 diabetes mellitus in men and women from the general population. Journal of Internal Medicine, 258, 527-535.

Middelberg, R. P., Martin, N. G., \& Whitfield, J. B. (2007). A longitudinal genetic study of plasma lipids in adolescent twins. Twin Research and Human Genetics, 10, 27-135.

Miura, K., Nakagawa, H., Nakamura, H., Tabata, M., Nagase, H., Yoshida, M., \& Kawano, S. (1994). Serum gamma-glutamyl transferase level in predicting 
hypertension among male drinkers. Journal of Human Hypertension, 8, 445-449.

Nakanishi, N., Nishina, K., Li, W., Sato, M., Suzuki, K., \& Tatara, K. (2003). Serum gamma-glutamyltransferase and development of impaired fasting glucose or type 2 diabetes in middle-aged Japanese men. Journal of Internal Medicine, 254, 287-295.

Nance, W. E., Bodurtha, J., Eaves, L. J., Hewitt, J., Maes, H., Segrest, J., Meyer, J., Neale, M., \& Schieken, R. (1998). Models for the longitudinal genetic analysis of same-age twins: Application to HDL cholesterol. Twin Research, 1, 3-8.

Nannipieri, M., Gonzales, C., Baldi, S., Posadas, R., Williams, K., Haffner, S. M., Stern, M. P., \& Ferrannini, E. (2005). Liver enzymes, the metabolic syndrome, and incident diabetes: The Mexico City diabetes study. Diabetes Care, 28, 1757-1762.

Neale, M. C. (1999). Mx: Statistical modeling (5th ed.). Richmond, VA: Department of Psychiatry, Medical College of Virginia.

Neale, M. C. \& Cardon, L. R. (1992). Methodology for genetic studies of twins and families. Dordrecht: Kluwer Academic Publishers.

Perry, I. J., Wannamethee, S. G., \& Shaper, A. G. (1998). Prospective study of serum gamma-glutamyltransferase and risk of NIDDM. Diabetes Care, 21, 732-737.

Pompella, A., Emdin, M., Passino, C., \& Paolicchi, A. (2004). The significance of serum gamma-glutamyltransferase in cardiovascular diseases. Clinical Chemistry and Laboratory Medicine, 42, 1085-1091.

Ruttmann, E., Brant, L. J., Concin, H., Diem, G., Rapp, K., \& Ulmer, H. (2005). Gamma-glutamyltransferase as a risk factor for cardiovascular disease mortality: An epidemiological investigation in a cohort of 163,944 Austrian adults. Circulation, 112, 2130-2137.

Snieder, H., van Doornen, L. J., \& Boomsma, D. I. (1999). Dissecting the genetic architecture of lipids, lipoproteins, and apolipoproteins: Lessons from twin studies. Arteriosclerosis, thrombosis, and vascular biology, 19, 2826-2834.

StataCorp. (2001). Stata statistical software (Release 7.0) [Computer software]. College Station, TX: Stata Corporation.

Tomita, M., Mizuno, S., Yamanaka, H., Hosoda, Y., Sakuma, K., Matuoka, Y., Odaka, M., Yamaguchi, M., Yosida, H., Morisawa, H., \& Murayama, T. (2000). Does hyperuricemia affect mortality? A prospective cohort study of Japanese male workers. Journal of Epidemiology, 10, 403-409.

Vozarova, B., Stefan, N., Lindsay, R. S., Saremi, A., Pratley, R. E., Bogardus, C., \& Tataranni, P. A. (2002). High alanine aminotransferase is associated with decreased hepatic insulin sensitivity and predicts the development of type 2 diabetes. Diabetes, 51, 1889-1895.

Wannamethee, G., Ebrahim, S., \& Shaper, A. G. (1995). Gamma-glutamyltransferase: Determinants and association with mortality from ischemic heart disease and all causes. American Journal of Epidemiology, 142, 699-708.

Wannamethee, S. G., Shaper, A. G., Lennon, L., \& Whincup, P. H. (2005). Hepatic enzymes, the metabolic syndrome, and the risk of type 2 diabetes in older men. Diabetes Care, 28, 2913-2918.

Whitfield, J. B. (2001). Gamma glutamyl transferase. CRC Critical Reviews in Clinical Laboratory Sciences, 38, 263-355.

Whitfield, J. B. \& Martin, N. G. (1983). Inheritance and alcohol as factors influencing plasma uric acid levels. Acta geneticae medicae et gemellologiae, 32, 117-126.

Whitfield, J. B., Zhu, G., Nestler, J. E., Heath, A. C., \& Martin, N. G. (2002). Genetic covariation between serum gamma-glutamyltransferase activity and cardiovascular risk factors. Clinical Chemistry, 48, 1426-1431.

Wilding, P., Rollason, J. G., \& Robinson, D. (1972). Patterns of change for various biochemical constituents detected in well population screening. Clinical Chimic Acta, 41, 375-387.

Wright, M., De, G. E., Ando, J., Luciano, M., Posthuma, D., Ono, Y., Hansell, N., Van, B. C., Hiraishi, K., Hasegawa, T., Smith, G., Geffen, G., Geffen, L., Kanba, S., Miyake, A., Martin, N., \& Boomsma, D. (2001). Genetics of cognition: Outline of a collaborative twin study. Twin Research, 4, 48-56.

Wright, M. J. \& Martin, N. G. (2004). Brisbane Adolescent Twin Study: Outline of study methods and research projects. Australian Journal of Psychology, $56,65-78$.

Zhu, G., Duffy, D. L., Eldridge, A., Grace, M., Mayne, C., O'Gorman, L., Aitken, J. F., Neale, M. C., Hayward, N. K., Green, A. C., \& Martin, N. G. (1999). A major quantitative-trait locus for mole density is linked to the familial melanoma gene CDKN2A: A maximum-likelihood combined linkage and association analysis in twins and their sibs. American Journal of Human Genetics, 65, 483-492. 